\title{
PLC Based Multi Starter Control using Single Control System for Induction Motor
}

\author{
S.Usha, C.Subramani, M.Venkatesan, S.Dhanush ragav, B.Aasif Imraan
}

\begin{abstract}
Most customarily used motor in the industries are induction motor due to its low cost, robustness and less maintenance. The change in the existing framework is necessary in order to make the motor more efficient one. This paper cast enlightenment about the PLC based 3 phase multi-starter control induction motor with energy efficient single control system. In order to start the engine's operation by its own power, starters are used. Various starters are available to initiate the 3-phase induction motor namely Direct On-line, Star-delta, autotransformer and rotor impedance. The employment of this PLC based techniques helps to increase the energy efficiency of the motor.The employability of PLC in this system is to help in the growth of automation. The hardware and software results of the multi starter control using single control systems are analysed.
\end{abstract}

\section{INTRODUCTION}

Effectiveness of the motor varies according to the starter used .In order to the satisfies the requirement for the customers, and Increase in the energy and cost efficiency of the motor one has to provide the proper type of starter for the existing type of motor. To overcome this, PLC based multi starter control using single control system for induction motor has been implemented. The employment of this PLC based techniques helps to increase the cost and energy efficiency of the motor and the starters are switched in order for their requirements for a better efficiency. These PLC based multi starter control using single control system, helps to switch the starter easily when it is in operating condition.

Automation is usually done in order for a better efficiency of cost and energy, and to operate in a safely working condition [1].PLC is used here as it provide greater flexibility. The error diagnosis is easy and can be corrected in the working condition itself.[4] .PLC came into existence with the name of MODICAN084 and the main man in the invention of PLC was Dick Morley and later he was considered as the Father of the PLC[5][6]. PLC is programmed using ladder diagram for intelligent switching between the two starters.[7]

Revised Version Manuscript Received on 10 September, 2019.

S.Usha, Department of Electrical and Electronics Engineering, SRM Institute of Science and Technology, Kattankulathur, Chennai, Tamilnadu, India.

C.Subramani, Department of Electrical and Electronics Engineering, SRM Institute of Science and Technology, Kattankulathur, Chennai, Tamilnadu, India.

M.Venkatesan, Department of Electrical and Electronics Engineering, SRM Institute of Science and Technology, Kattankulathur, Chennai, Tamilnadu, India.

S.Dhanush ragav, Department of Electrical and Electronics Engineering, SRM Institute of Science and Technology, Kattankulathur, Chennai, Tamilnadu, India.

B.Aasif Imraan, Department of Electrical and Electronics Engineering, SRM Institute of Science and Technology, Kattankulathur, Chennai, Tamilnadu, India.
This project deals with energy efficient and helps in the reduction of the cost by using a single control system for various type of motors, that is the multi starter control, that can be used for the operation of star delta and DOL type sttarters.So that, cost gets reduced even though the working operation is considered same. In order to make user friendly and ease of using the introduction of mobile controller that makes this more useful for the switching operation. Usage of PLC over soft starter, because this produces the harmonics in a large amount compared to PLC

\section{HARDWARE COMPONENT AND ITS DESCRIPTION}

\section{A) PLC:}

The Relay is used in industries mainly in the manufacturing process .As it consume a large amount of power and required to be replaced frequently, they have been replaced by PLC. They are form of digital computer which is used in electromechanical process to enable automation. PLC are reliable under harsh environmental conditions and are programed using the given programming language on a computer and are transferred to the PLC using a cable. The program is referred by a ladder logical diagram and SELECT PLC brand is used to keep the cost low.

\section{b) HC O6 BLUETOOTH MODULE:}

This is a pair of slave Bluetooth module, which is used universally for wireless serial communication. This is paired along with a master Bluetooth module in a laptop or phone and the communication of data can take place. All the data received and transmitted are in real time.

c) ARDUINO ATMEGA328P:

It consist of 8 bit AVR Risc based microcontroller. They can used in places where there is a need of simple, low cost microcontroller.

\section{d) RELAY:}

These are usually made up of electromagnets, which in general purpose used as a switch. The working of relay is simple, the signals that are obtained from the one end of the device controls the switching operation of the other end of the device. Their main operation is to break the contact of the signal without the human involvement of switching operation .The working is done with the control of high powered circuit using a low powered circuit.

\section{Published By:}




\section{1) Direct On-Line (DOL) starter :}

DOL is a simple and economical starter and is widely used in squirrel cage induction motor. It directly interfaces the contacts of the engine to the full supply voltage. The starting current is exceptionally extensive, usually as 6 times the evaluated current. The initial torque is probably going to be 0.75 times the full load torque.

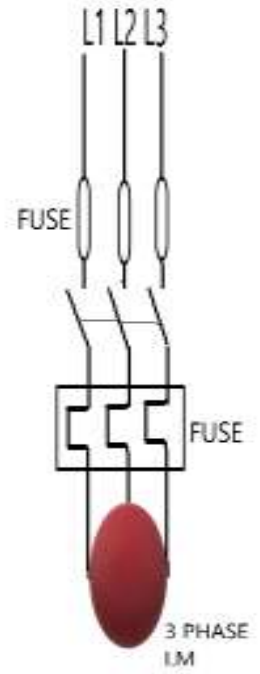

Fig 1 DOL starter

\section{2)Star-Delta Starter:}

The star delta starter is a most commonly used type of starter in starting of the induction motor. Working of star delta starter is simple when the switch is in start position the stator winding connected in star. While the motor attains the speed which is about $80 \%$ of the rated speed .They are switched into delta connections, while in this condition the starting line current is one third compared to the starting current accompanied winding connected in the delta.In case of the star delta starter ,the developed torque is directrly

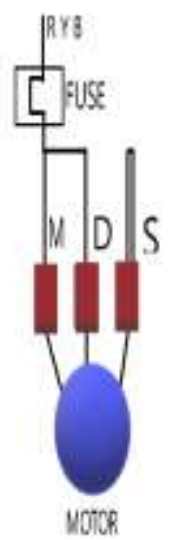

Fig:2 ( Model to Star delta)

\section{3) Synthesi of Star delta and DOL using PLC:}

The SELECT brand in PLC has been used,since it is cheap when compared to other type of brand in PLC. Usage of a self pro software for programming regarding PLC has been executed.This software slightly differ from RS LOGIC 500. This software helps in programming the ladder diagram. The circuit has been designed which helps in switching between the star delta and DOL starter using selector switch .In the propotional to the square of the voltage.

selector switch,$\uparrow$ arrow indicates Star delta function whereas $\downarrow$ arrow indicates DOL starter. When the selector switch is in star delta mode, $\mathrm{M}$ coil and $\mathrm{S}$ coil closes, it indicates the star current has been passed.It has been designed in such a way, after 5 seconds $\mathrm{M}$ coil and $\mathrm{S}$ coil opens and D coil gets closed and delta current is passed. If it is tried to be managed in parallel aspect the starter will get damaged. So the seconds are maintained in order to avoid damage. This damage will not be carried away to the DOL because of the usage of the selector positioning switch. When the $\downarrow$ arrow is pulled down The DOL is started so there will be no damage to the Star delta .In DOL starter M and S coil opens and D coil closes and starts the motor. The functions of both star delta and DOL circuit has been programmed in a single ladder diagram When both circuit is operating together there is a chance of receiving a high current. In order to avoid that programming is made in the OVER LOAD CURRENT RELAY in the M coil.

\section{4) LADDER DIAGRAM:}

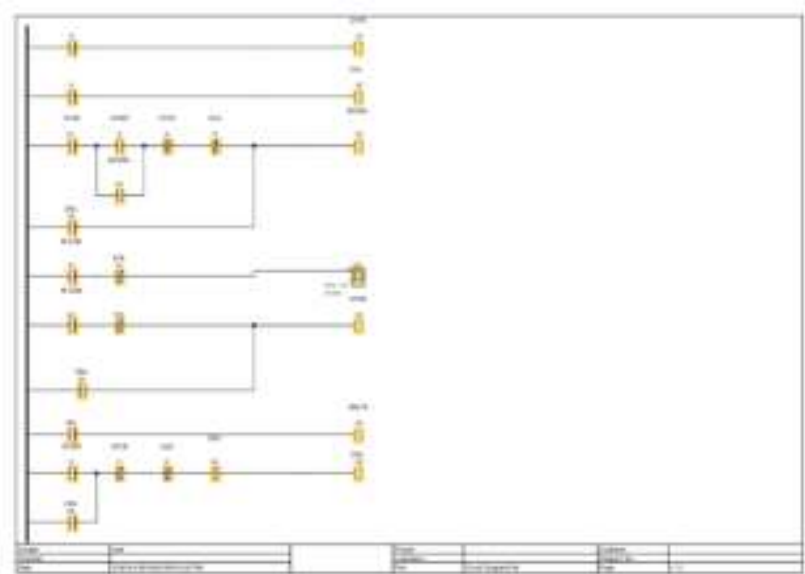

Fig:3 simulation of proposed model

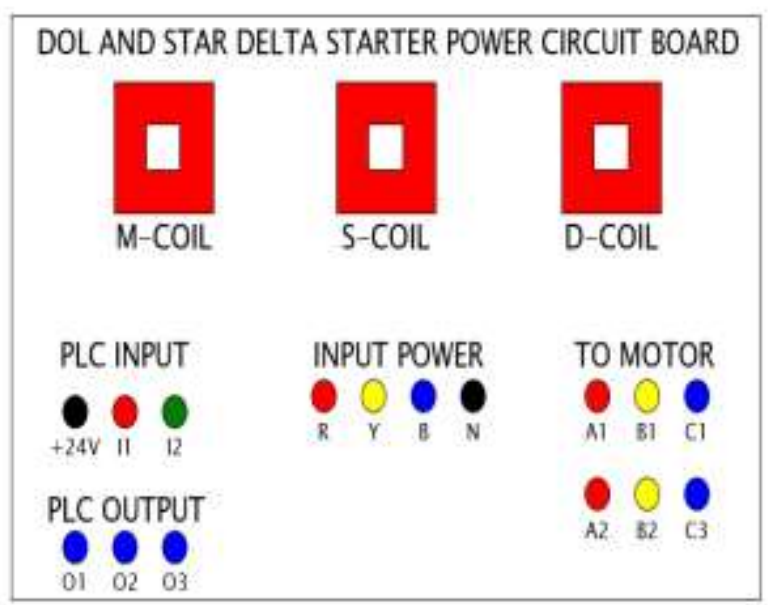

Fig:4 control panel design of proposed model

Published By: Blue Eyes Intelligence Engineering 
Fig 3 simulation of proposed model represents the combination of star delta and DOL using PLC ladder simulation diagram. Fig 4 control panel design of proposed model represents the vision of panel board diagram which includes the combination of DOL and Star delta starter with the advantages of having input and output of the motor and starter, with the usage of less wires compared to other .

\section{5) DOL:}

\section{NO LOAD CONDITION:}

\begin{tabular}{|l|l|l|l|l|l|l|l|l|l|l|l|}
\hline V & A & W1 & W2 & S1 & S2 & RPM & I & OP & PF & 1\% & SSlip \\
\hline 210 & 2.1 & 400 & 640 & 2 & 2 & 1495 & 0 & 0 & 0.804 & 63.14 & 2 \\
\hline
\end{tabular}

\section{Table1: No load test}

This test is usually done in order to determine the efficiency and to note the value of the circuit parameters of the three phase induction motor .And with help of the device, two wattmeter power is note down and is represented as $\mathrm{W} 1, \mathrm{~W} 2$.When the motor is in running condition the input power should be equal to the constant iron, friction and windage loss of the three phase induction motor

\section{LOADED CONDITION:}

\begin{tabular}{|c|c|c|c|c|c|c|c|c|c|c|c|}
\hline & & $\pi 1$ & WI2 & 81 & 52 & RPMI & & $O P$ & $\mathrm{PF}$ & $\%$ & \\
\hline 210 & $\cdots$ & & 410 & 8 & 0.1 & 1522 & 16.75 & 203 & 0.336 & & \\
\hline & 2 & 8 & 30 & 7 & 02 & 1448 & 6037 & 909 & 0.1273 & & 1 \\
\hline & 4.5 & 100 & 60 & 10 & $\uparrow$ & 1440 & 84.78 & 127 & 0.8088 & & \\
\hline
\end{tabular}

Table 2:Performance of induction motor under load test

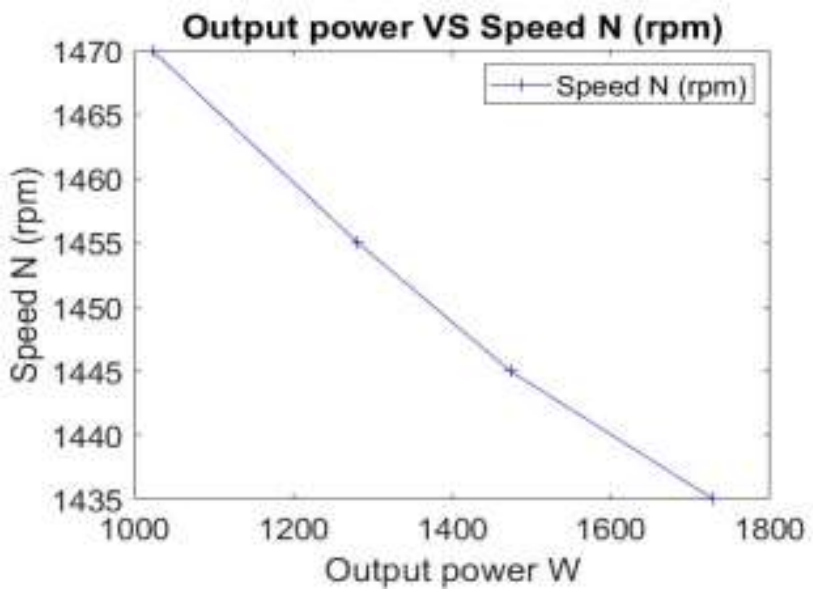

Fig:5 Speed performance

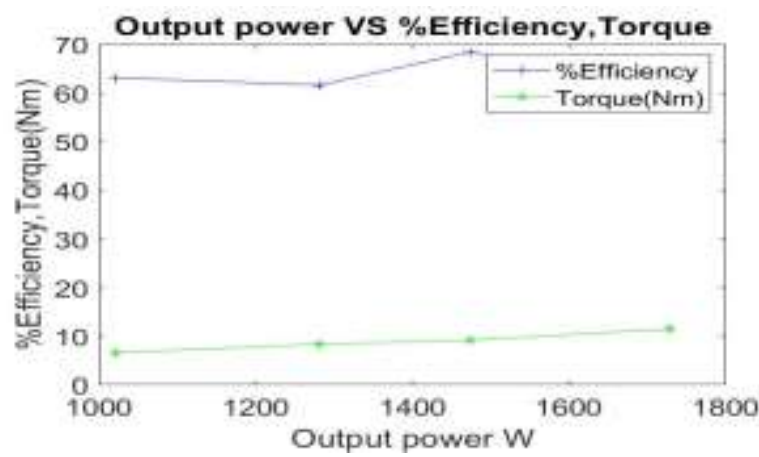

Fig.no:6 Efficiency and torque performance of induction motor

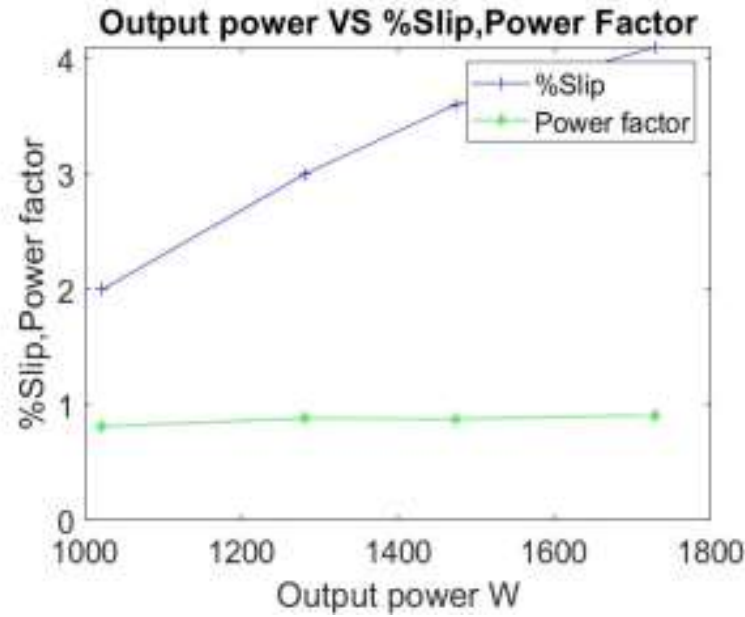

Fig:7 Power factor of induction motor

Fig no 5 represents the output power in the $\mathrm{x}$ axis and the speed in the y axis .output power is inversely proportional to the speed in the induction motor. This relation is reflected in the plotted graph .Fig 6 represents the output power in the $\mathrm{x}$ axis and efficiency and $\%$ torque in the y axis of the induction motor the efficiency is about $65 \%$ and the torque increases with increase in output power. This relation is reflected in the plotted graph. Fig 7 represents output power in the $\mathrm{x}$ axis and $\%$ slip and power factor in y axis. The ouput power is found to be directly proportional to the power factor. and slip. This relation is reflected in the plotted graph.

\section{Calculation:}

Output power $=2 * 3.14 * \mathrm{~N} * \mathrm{~T} / 60$

1. $2 * 3.14 * 1522 * 1.6775 / 60=265$

2. $2 * 3.14 * 1448 * 6.0037 / 60=909$

3. $2 * 3.14 * 1440 * 8.4758 / 60=1277$

4. $2 * 3.14 * 1436 * 11.47 / 60=1772$

Efficiency $=$ output/input $* 100 \quad, 3 \mathrm{hp}=750=3 * 750=$ 2250

1. $2250 / 220 * 100=63.4 \%$

2. $2250 / 210 * 100=61.6 \%$

3. $2250 / 240 * 100=68.4 \%$

4. $2250 / 300 * 100=62.2 \%$

Slip $=[\mathrm{Ns}-\mathrm{N} / \mathrm{Ns}] * 100, \mathrm{Ns}=3 \mathrm{hp}=3 * 750=1500$

1. $1500-1522 / 1500 * 100=1.4 \%$

2. $1500-1448 / 1500 * 100=3.46 \%$

3. $1500-1440 / 1500 * 100=4 \%$

4. $1500-1436 / 1500 * 100=4.2 \%$

Power factor $=$ input power/ $1.732 * \mathrm{~V} * \mathrm{I}$

1. $220 / 1.732 * 210 * 1.8=0.336$

2. $210 / 1.732 * 210 * 2.5=0.1273$

3. $210 / 1.732 * 210 * 4.5=0.808$

4. $210 / 1.732 * 210 * 6.5=0.1203$

Torque $=9.81 *(\mathrm{~s} 1-\mathrm{s} 2) * \mathrm{R} \mathrm{R}=0.9$

1. $9.81 *(2-0.1) * 0.9=16.7751$

2. $9.81 * 6.8 * 0.9=60.0372$

3. $9.81 *(10-0.4) * 0.9=84.78$

4. $9.81 *(14-1) * 0.9=114.72$ 


\section{6) STAR DELTA:}

Loaded Test:

\begin{tabular}{|l|l|l|l|l|l|l|l|l|l|l|}
\hline VI(V) & IL(A) & Input(W) & Load(S1) & Load(S2) & T(Nm) & $\begin{array}{l}\text { Speed } \\
\text { N } \\
(\mathbf{r p m})\end{array}$ & $\begin{array}{l}\text { Output } \\
\text { power } \\
(\mathbf{W})\end{array}$ & \%slip & \%n & Pf \\
\hline 210 & 1.9 & 170 & 5 & 0.2 & 42.37 & 1470 & 6519 & 2 & 38.3 & 0.1356 \\
\hline 210 & 2.3 & 210 & 10 & 0.3 & 85.6 & 1453 & 13010 & 3.1 & 61.9 & 0.1384 \\
\hline 210 & 2.7 & 290 & 12 & 0.4 & 102.41 & 1451 & 15553 & 3.2 & 53.5 & 0.1688 \\
\hline 210 & 3.0 & 360 & 16 & 0.7 & 135 & 1447 & 20456 & 3.5 & 50.7 & 0.1819 \\
\hline
\end{tabular}

Table 3:Inductiono motor load test using Star delta starter

\section{CALCULATION:}

$\mathrm{Slip}=[\mathrm{Ns}-\mathrm{N} / \mathrm{Ns}]^{*} 100$ $\mathrm{f}=50 \mathrm{~Hz} \quad \mathrm{p}=4$

1) $[1500-1470 / 1500] * 100=2 \%$

2) $[1500-1453 / 1500] * 100=3.1 \%$

3) $[1500-1451 / 1500] * 100=3.2 \%$

4) $[1500-1447 / 1500] * 100=3.5 \%$

Torque $=9.81 *(\mathrm{~s} 1-\mathrm{s} 2) * \mathrm{R}$

1) $9.81 * 4.8 * 0.9=42.379$

2) $9.81 * 9.7 * 0.9=85.6$

3) $9.81 * 11.6 * 0.9=102.41$

4) $9.81 * 15.3 * 0.9=135.0$

Output power $=2 * 3.14 * \mathrm{~N} * \mathrm{~T} / 60$

1) $2 * 3.14 * 1470 * 42.34 / 60=6519$

2) $2 * 3.14 * 1453 * 85.6 / 60=13018$

3) $2 * 3.14 * 1451 * 102.41 / 60=6519$

4) $2 * 3.14 * 1447 * 135 / 60=20446$

$\%$ Efficiency $=$ output/input $* 100$

output is $3 \mathrm{hp}$ $3 * 750=2250$

1) $2250 / 170 * 100=13.2$

2) $2250 / 210 * 100=10.7$

3) $2250 / 290 * 100=7.75$

4) $2250 / 360 * 100=6.25$

Power factor =input power/3.14*V*I

1) $170 / 3.14 * 1.9 * 210=0.1356$

2) $210 / 3.14 * 2.3 * 210=0.13842 \cdots$

3) $290 / 3.14 * 2.7 * 210=0.1628$

4) $360 / 3.14 * 3 * 210=0.1819$

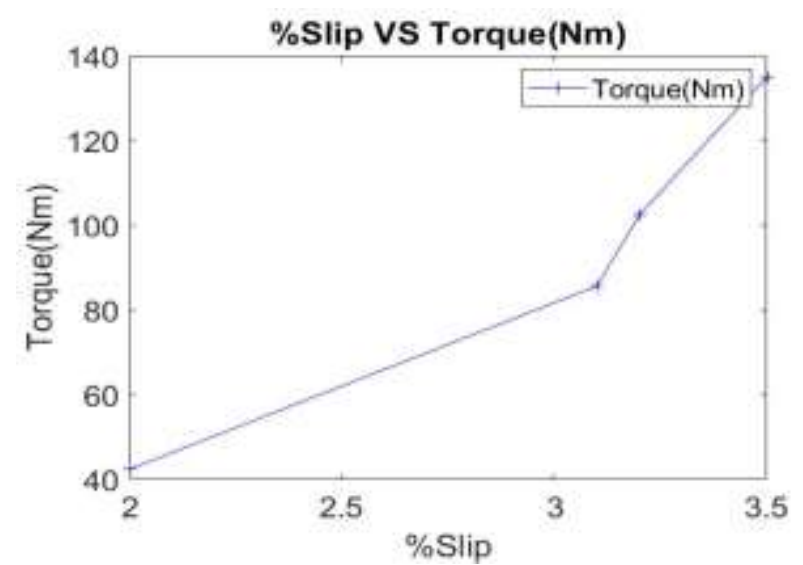

Fig No.8 Torque performance of induction motor using star delta starter

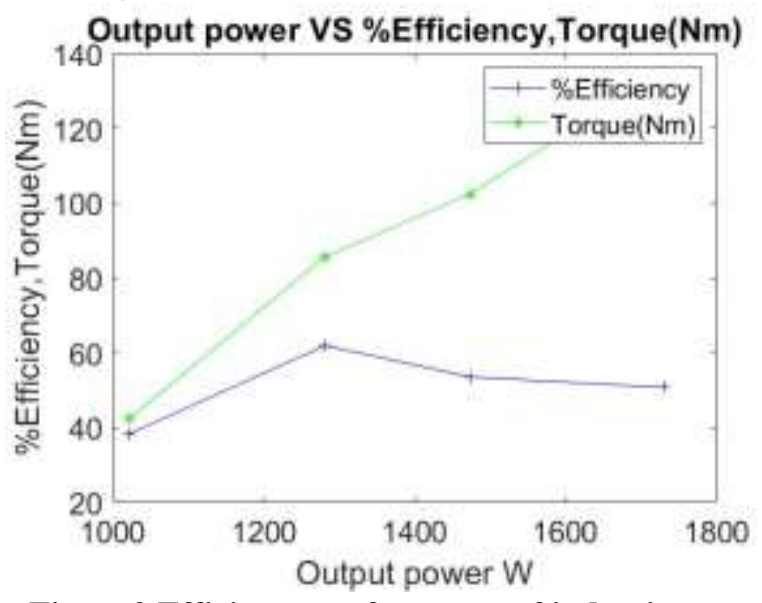

Fig no.9 Efficiency performance of induction motor using star delta starter

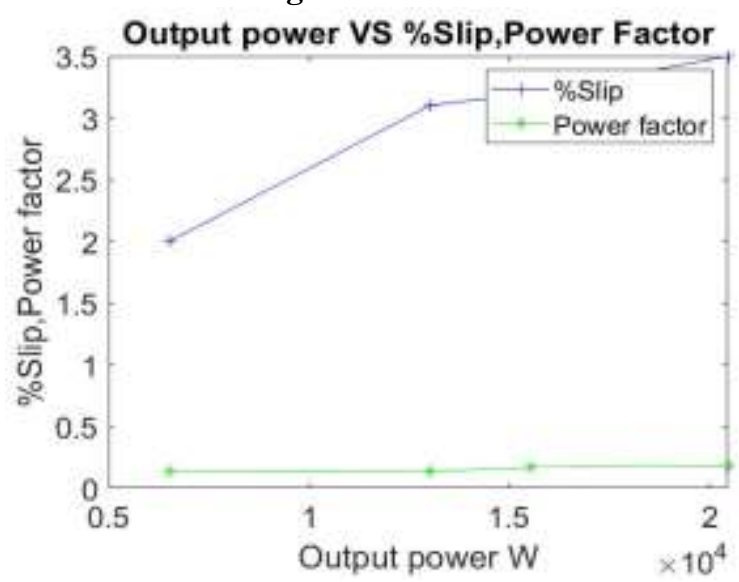

Fig No.10 Power factor of induction motor using star delta starter

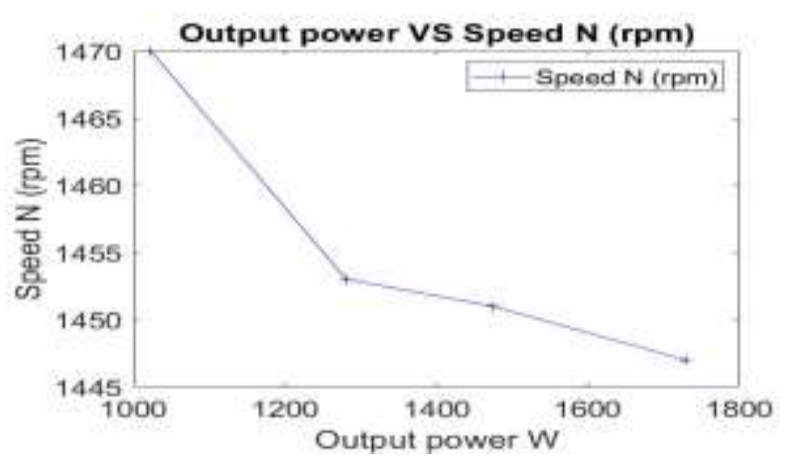

Fig No.11 Speed performance of induction motor

Published By:

Blue Eyes Intelligence Engineering 
Fig 8 represents the relationship between the slip in $\mathrm{x}$ axis and torque of the three phase induction motor in the y-axis .The torque is directly proportional to slip. this relation is reflected in the plotted graph. Fig 9. represents the relationship between the output power in $\mathrm{x}$ axis and efficiency and torque in $y$ axis of the induction motor the output power is directly proportional to torque but the efficiency remains the same. Fig. 10 represents the relationship between the output power in $\mathrm{x}$ axis and slip and power factor in the $\mathrm{y}$ axis. The output power is directly proportional to slip and power factor that is increases in output power causes increases the slip and power factor. Fig 11 represents the relationship between the output power in $\mathrm{x}$ axis and speed in $y$ axis of the three phase induction motor . The output power is indirectly proportional to speed.

\section{III.PROPOSED MODEL \& RESULTS}

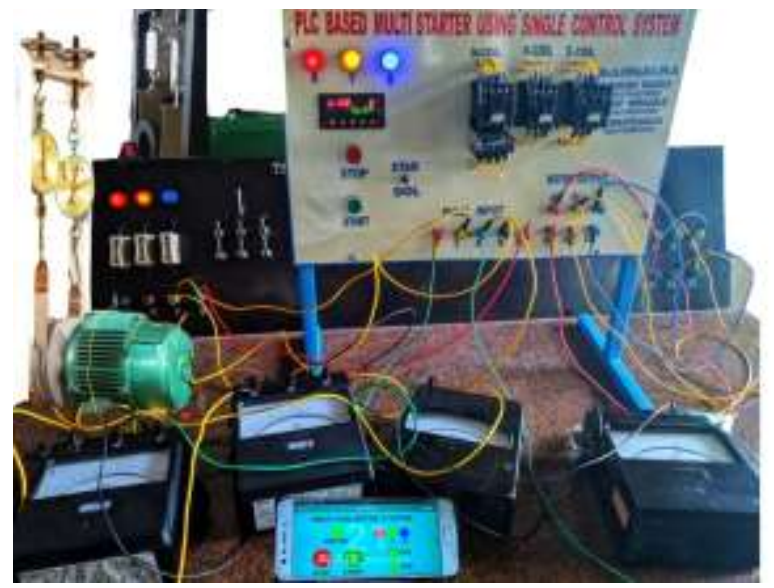

Fig12.Proposed system model

Fig 12 represents the manual implementation of fig 4.In order to make advance in this implementation ,mobile starter controller has been implemented. This helps to switch ON and OFF through Wi-Fi, Bluetooth. This also indicates fault, overload current , and incase any other fault, it indicates by displaying PRE in the color of red. The program used in SELFPRO is also used in Arduino programming from that it is connected to the mobile application through Bluetooth module.

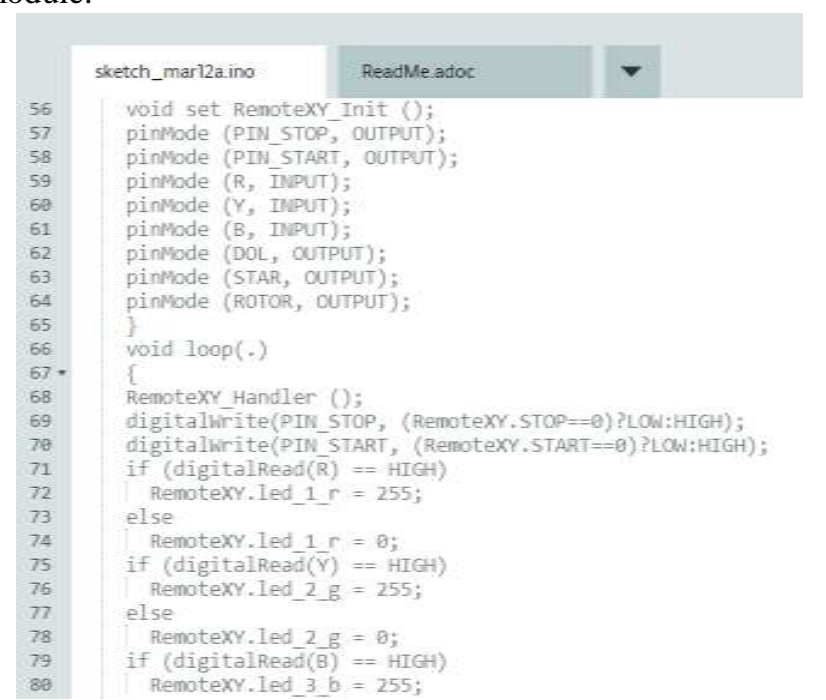

Fig:13 represents the sample of Arduino program for mobile application.

\section{1)MOBILE CONTROLLER:}

In paper and pulp industries, the operation is fully enclosed in a closed surface, in order for the human to take measure the reading is difficult, so once the manual switch is on, in this case mobile application is useful.It is controlled through Remote XY application software.

Mobile starter controller is used to control electric motors agricultural pump sets with the help of GSM technology. It allows for switching on and off of a electric devices. Applications are air break contractor, old button starter oil cooled starter.It can be used on any pump set like mono block open well submersible and bore well submersible pump sets.It should be used with the power range of 0.5 to $100 \mathrm{HP}$ pump sets.

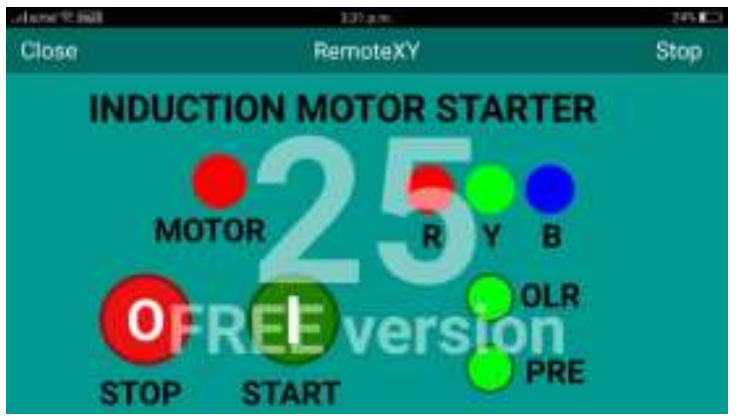

Fig no.14 represents the normal working condition of REMOTE XY APPLICATION

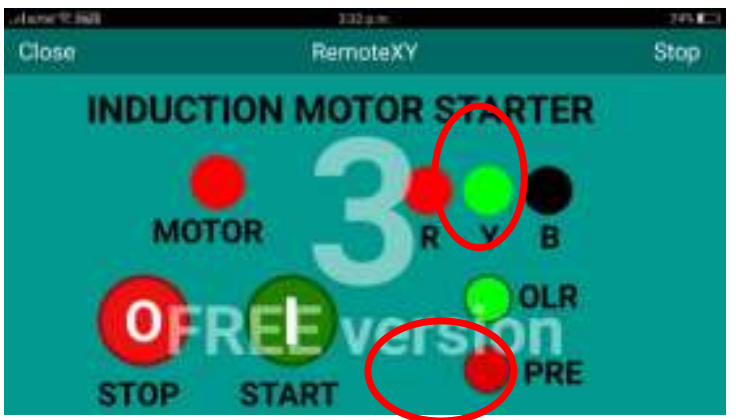

Fig 15 Fault analysis of proposed model

In Fig:15 ,Three phases R,Y,B indicated by red, green, and blue but in case of fault occurred in any of the phases it indicates through black color. In case of any fault occurs, PRE is indicated by RED color.This Mobile application can be used in every android smartphones.The Start and Stop button in this App indicates the start of the induction motor and stop of the induction motor.

\section{IV.CONCLUSION}

A project has been done with all the required functions.As said earlier,the mobile controller also has been made on this invention with almost swithching on and off is possible and the Remote XY App works on every android smartphones. Almost all the features of the App have been designed and Implemented. It can be accessed from that mobile phones and password can be assigned for the security purposes, alert interruption , number of phases functioning currently ,alerts switching on and off of pump set and protects it from dry run 
phase failure low voltage and phase imbalance this allows for saving time and energy for the farmers.This cost efficient control system is useful for many applications .Thus project has been done for reducing the cost purposes and user friendly purposes.

\section{REFERENCES}

1 Sanjiv Kumar, faculty in EED HBTI, Kanpur, Devendra Kumar, student of HBTI EED, Vikash Saini, student of HBTI EED, Jitendra Kumar, student of HBTI EED, "INDUSTRIAL AUTOMATION SYSTEM". XXXII National Conference, NSC 2008, December 17-19, 2008.

2 Shruti Kharait* , Prof. Sudhir Phulambrikar, Implementation of PLC Based Star Delta Starter for Starting and Direction Control Of Three Phase Induction Motor

3 Akshay P. Shinde1, Kiran S.Shendge2, Ranjit K.More3, Prof.Prashant B.Pawar4 Dept. of Electrical , PLC AUTOMATION OF STAR DELTA STARTER FOR USING INDUCTION MOTOR Engineering, SPVP's S.B. Patil College of Engineering, SPPU,

4 Sadegh vosough1 and Amir vosough2 "PLC and its applications". International Journal of multidisciplinary sciences and engineering, vol. 2, no.8 November 2011.

5 Nidhi Phadnis, M.E. SATI, Shruti Kharait, M.E. SATI, Devesh Tamrakar, M.E. SATI, Prof. Sudhir Pulambrikar, HOD Electrical Department SATI"PLC and its applications to control single phase induction motor". INTERNATIONAL JOURNAL OF ENGINEERING SCIENCES \& M6ANAGEMENT (Vol. 3, Issue 3) JulySep2013.

6 Saurabh Sharma and T.Y.Ladakhi, Assistant Professor-II Mech. Engg. Dept SMIT, Majitar, A.P.Tiwary and R.Phipon, Associate Professor Mech. Engg. Dept SMIT, Majitar, Dr. B.B.Pradhan Professor Mech. Engg. Dept SMIT, Majitar, "Application of PLC for Elevator Control System" International Symposium on Devices MEMS, Intelligent Systems \& Communication (ISDMISC) 2011 Proceedings published by International Journal of Computer Applications ${ }^{\circledR}$ (IJCA).

7 Design and implementation of a PLC based Electrical supply switching control system .OSR Journal of Electrical and Electronics Engineering (IOSR-JEEE) .e-ISSN: 2278-1676,p-ISSN: 2320-3331, Volume 11, Issue 3 Ver. III (May. - Jun. 2016), PP 43-50

8 Microcontroller based speed control of three phase induction motor using v/f method. International Journal of Scientific and Research Publications, Volume 3, Issue 2, February 2013

9 Yasar Birbir, H.Selcuk Nogay, "Design and Implementation of PLC-Based Monitoring Control System for Three-Phase Induction Motors Fed by PWM Inverter", international journal of systems applications, engineering \&development, 2( 3), 2008

10 10) Ali Gulabi," Development of an Embedded SCADA System with PLC and Java Application for Synchronous Operation of Standard Servo Drives", Master thesis Faculty of Engineering and Computer Science of the University of Applied Sciences Hamburg, May 2007.

11 Rinchen Geongmit Dorjee, "Monitoring and Control of a Variable Frequency Drive Using PLC and SCADA", International Journal on Recent and Innovation Trends in Computing and Communication, 2 (10), October 2014D.

12 S.Green,D.J.Atkinson,A.G .Jack B.C.Mecrow, and A.king,'Sensorless operation of a fault tolerant PM drive ','IEEE Trans. magnetics,vol.39,no.5,2003,pp.2962-2964.

13 J.B. Wang, K. Atallah, and D. Howe, "Optimal torque control of fault-tolerant permanent magnet brushless machines," IEEE Trans. on Magnetics, Vol. 39, No. 5, 2003, pp. 2962-2964.

14 S.Gataric, "A polyphase Cartesian vector approach to control of polyphase AC machines," Proc. IEEE Ind. Appl. Soc. Annual Meeting IAS, Rome, Italy, 2000, Paper no. 38-02.

15 A.R. Kashif and M.A. Saqib, "Soft starting of an induction motor using adaptive neuro fuzzy interface system", Proc. Int. conf. on Electrical Engg., ICEE 07, pp. 1-5,11-12 April 2007.J.B. Wang, K. Atallah, and D. Howe, "Optimal torque control of fault-tolerant permanent magnet brushless machines," IEEE Trans. on Magnetics, Vol. 39, No. 5, 2003, pp. 2962-2964.

16 S.Gataric, "A polyphase Cartesian vector approach to control of polyphase AC machines," Proc. IEEE Ind. Appl. Soc. Annual Meeting IAS, Rome, Italy, 2000 , Paper no. 38-02.[5] A.R. Kashif and M.A. Saqib, "Soft starting of an induction motor using adaptive neuro fuzzy interface system", Proc. Int. conf. on Electrical Engg., ICEE 07, pp. 1-5,11-12 April 2007

\section{APPENDICES}

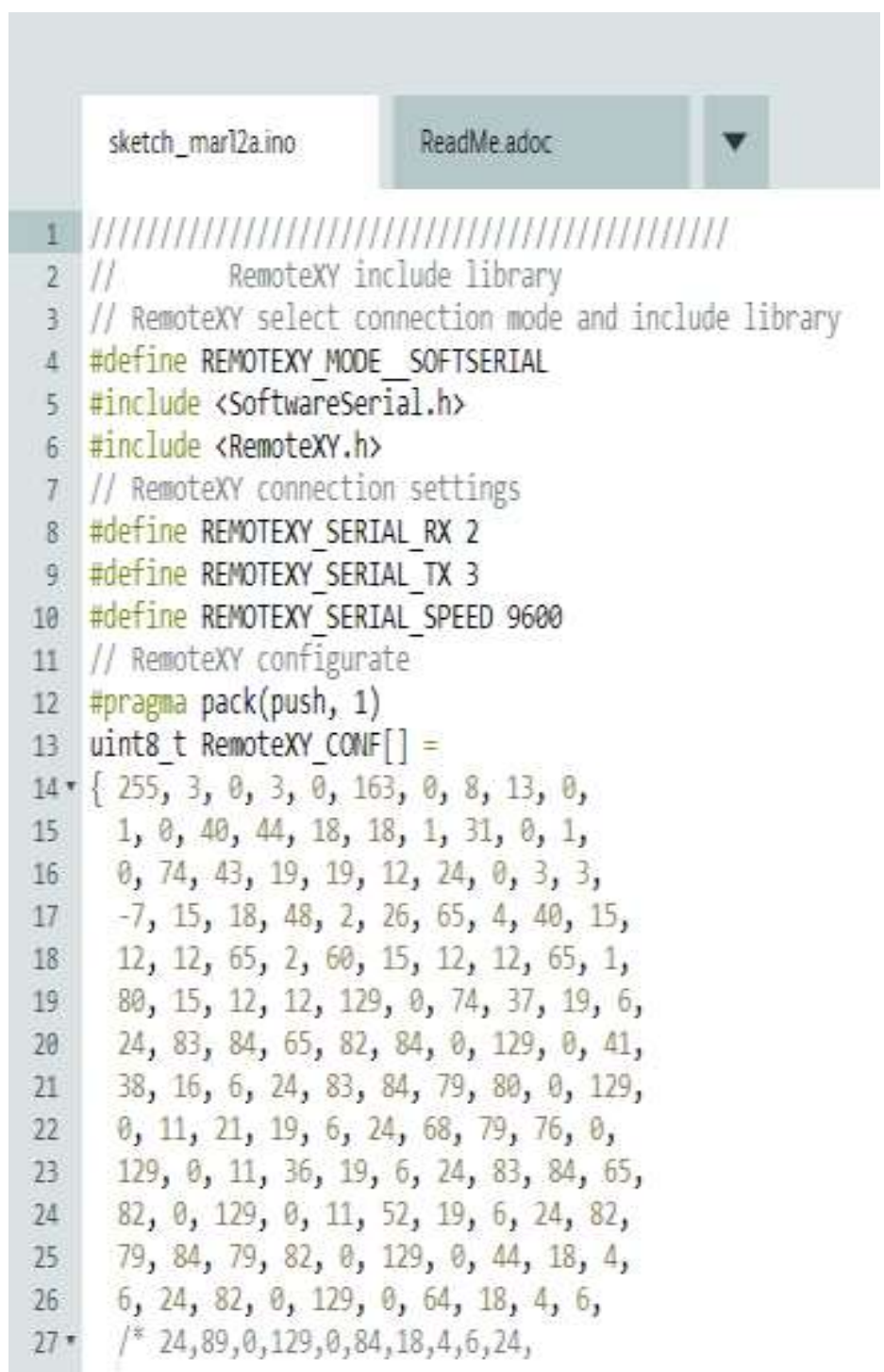



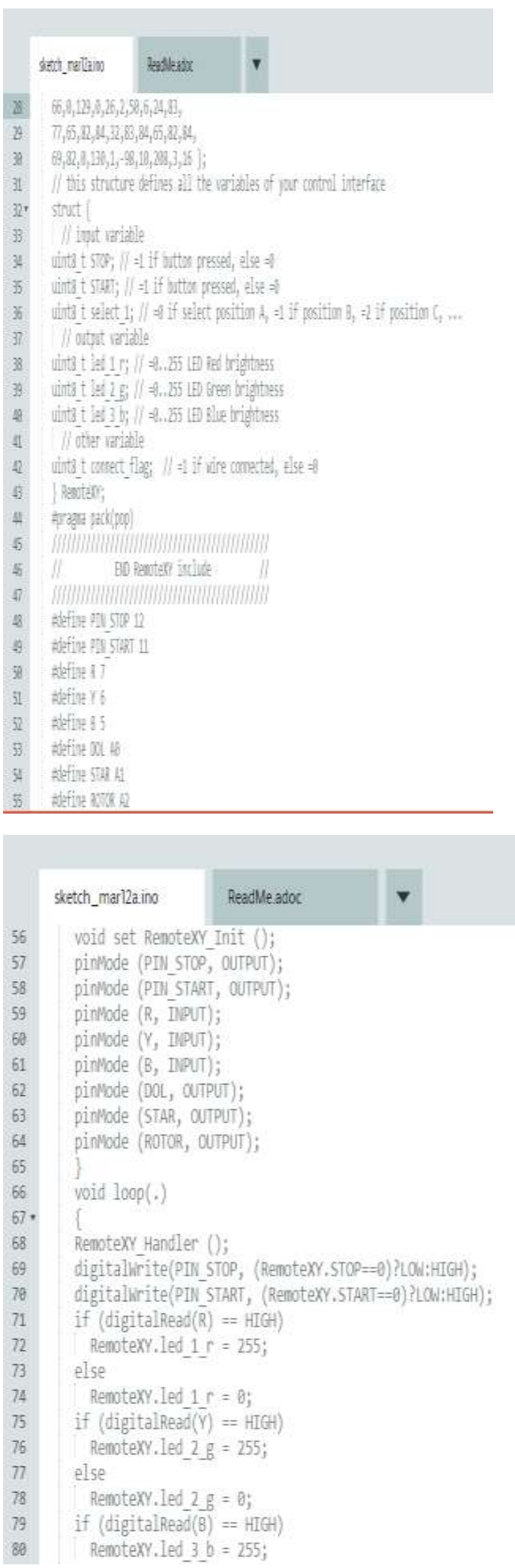

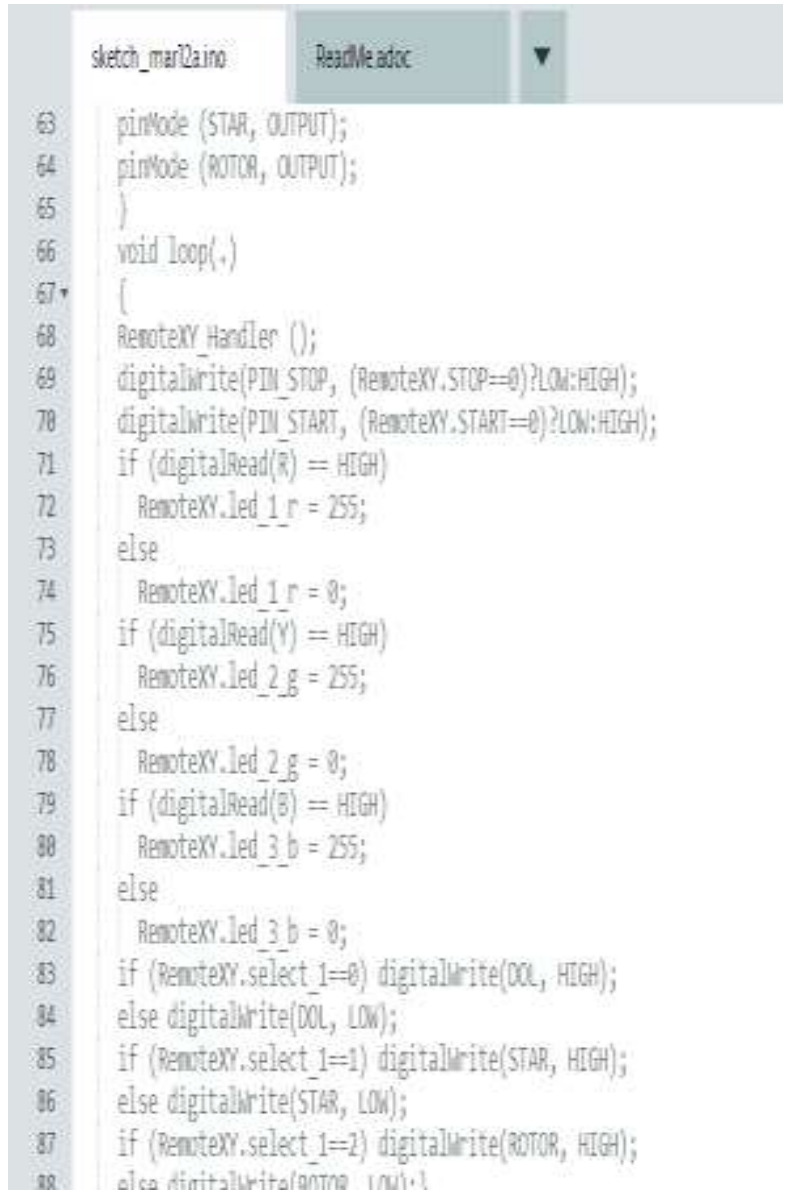

